\title{
O ENSINO DE GEOGRAFIA E O TURISMO: UMA PROPOSTA DE PERCEPÇÃO DO NOVO USO E APROPRIAÇÃO DO ESPAÇO NO DISTRITO DE GARDÊNIA, MUNICÍPIO DE RANCHARIA/SP
}

\author{
Sueli Aparecida de Souza ${ }^{1}$
}

\author{
Rosângela Custodio Cortez Thomaz
}

\section{RESUMO}

A geografia tem se apresentado como uma ciência aberta aos diversos campos de estudo na contemporaneidade, assim, tem contribuído significativamente na compreensão dos rebatimentos dessa da atividade turística no espaço. Desse modo, pretende-se com esse estudo, desdobrado de um Projeto de Pesquisa ${ }^{3}$, enfatizar a relevância de se traçar um diálogo entre a educação e o turismo em localidades inseridas num contexto de mudanças no uso e apropriação do espaço pela atividade turística. Partimos da ideia de que por meio da abordagem geográfica possibilitaremos que os alunos do 9o ano de uma escola municipal no Distrito de Gardênia, Município de Rancharia/SP, apreendam e percebam as implicações dessa nova dinâmica nas práticas espaciais locais. Assim, quanto a questão metodológica, o estudo assume conjuntamente um caráter exploratório descritivo, com revisão bibliográfica, documental e pesquisa empírica. Com base nas investigações, foi possível observar que o envolvimento, a inserção dos professores e alunos como colaboradores nas pesquisas que estão sendo desenvolvidas, assim como as tabulações e devolutivas, são ferramentas promissoras para a aprendizagem significativa sobre o próprio lugar dos sujeitos.

PALAVRAS-CHAVE: Ensino. Reestruturação produtiva. Analise geográfica do turismo.

\section{THE THEACHING BY GEOGRAPHI THE TOURISM: A PROPOSAL FOR A NEW PERCEPTION OF USE AND}

\footnotetext{
${ }^{1}$ Formação acadêmica, instituição e/ou cargo. E-mail.

${ }^{2}$ Formação acadêmica, instituição e/ou cargo. E-mail.

${ }^{3}$ Projeto de Pesquisa intitulado de "A PERCEPÇÃO DO LUGAR NO ENSINO DE GEOGRAFIA: UMA PROPOSTA DE CONTRIBUIÇÃO PARA A SENSIBILIZAÇÃO TURÍSTICA NO DISTRITO DE GARDÊNIA, MUNICÍPIO DE RANCHARIA/SP".
} 


\title{
Periódica Eletrônica ISSN 1980-0827

\section{OWNERSHIP OF SPACE IN THE DISTRICT OF GARDÊNIA, MUNICIPALITY OF RANCHARIA/SP}

\begin{abstract}
Geography has been presented as an open science to various fields of study in contemporary times; thus, has contributed significantly in understanding the repercussions of this tourist activity in space. Thus, the aim of this study was unfolded of a Research Project, emphasizing the importance of drawing a dialogue between education and tourism in localities placed in the context of changes in the use and appropriation of space for tourist activity. We start from the idea that through geographic approach make possible that the 9th graders from a public school in the District of Gardênia, city of Rancharia / $\mathrm{SP}$, seize and realize the implications of this new dynamic in local spatial practices. Thus, as the methodological issue, the study jointly assumes a theoretical, descriptive, and literature review and empirical research. Based on the investigations, it was observed that the involvement, the inclusion of teachers and students as collaborators in the research being undertaken, as well as tabs and then fed back, are promising for meaningful learning about the place of the subject's own tools.
\end{abstract}

KEY WORDS: Teaching. Productive restructuring. Geographical analysis of tourism.

\section{LA ENSEÑANZA DE LA GEOGRAFÍA Y TURISMO : UNA PROPUESTA PARA UNA NUEVA PERCEPCIÓN DE USO Y PROPIEDAD DE ESPACIO EN EL DISTRITO DE GARDÊNIA, MUNICÍPIO DE RANCHARIA / SP}

\section{RESUMEN}

La geografía ha sido presentada como una ciencia abierta a los distintos campos de enseñanza en la contemporaneidad, por lo tanto ha contribuido significativamente en la comprensión de las repercusiones del turismo en el espacio. De esta manera, se pretende con ese estudio, desarrollado de un Proyecto de Investigación, enfatizar la relevancia de realizar un dialogo entre la educación y el turismo en localidades situadas en un contexto de cambios en el uso y la apropiación del espacio para la actividad turística. Partimos de la idea de que por medio del enfoque geográfico tenderemos la posibilidad de que los alumnos del $9^{\circ}$ grado de una escuela pública en el Distrito de Gardenia, ciudad de Rancharia/SP, aprendan y perciban las implicaciones de esta nueva dinámica en las prácticas espaciales locales. Así, en la cuestión metodológica, el estudio asume un carácter teórico, descriptivo con revisión bibliográfica y pesquisa empírica. Con base en estas investigaciones, se observó que la participación, la inclusión de los maestros y estudiantes como colaboradores en las investigaciones que están siendo desarrolladas, así como las tabulaciones y devolutivas, son herramientas significativas para el aprendizaje sobre el propio lugar de los sujetos.

PALABRAS-CLAVE : Enseñanza. Reestructuración productiva. Analice geográfica del turismo. 


\section{INTRODUÇÃO}

O intuito desse estudo é de evidenciar a relevância do diálogo entre turismo e educação considerando um contexto do uso e apropriação do espaço pelo turismo de pesca, sobretudo, e suas implicações nas práticas espaciais da comunidade local no Distrito de Gardênia, Município de Rancharia/SP.

A política de modernização da agricultura, a intensificação da urbanização e industrialização, frutos da política governamental instituída a partir da década de 1950, implicou mudanças nas mais diversas escalas geográficas. Novas relações entre campo e cidade foram suscitadas, como o reconhecimento, a partir da década de 1990, do caráter multifuncional do meio rural (HESPANHOL. A. N.; HESPANHOL, R. A. M).

Nesse contexto, Souza (2012) verificou que o Distrito de Gardênia (Figura 1) não ficou ileso aos rebatimentos dessas novas dinâmicas, tendo seu conteúdo socioespacial ${ }^{4}$ alterado significativamente.

Figura 1: Localização do Município de Rancharia e seus Distritos.

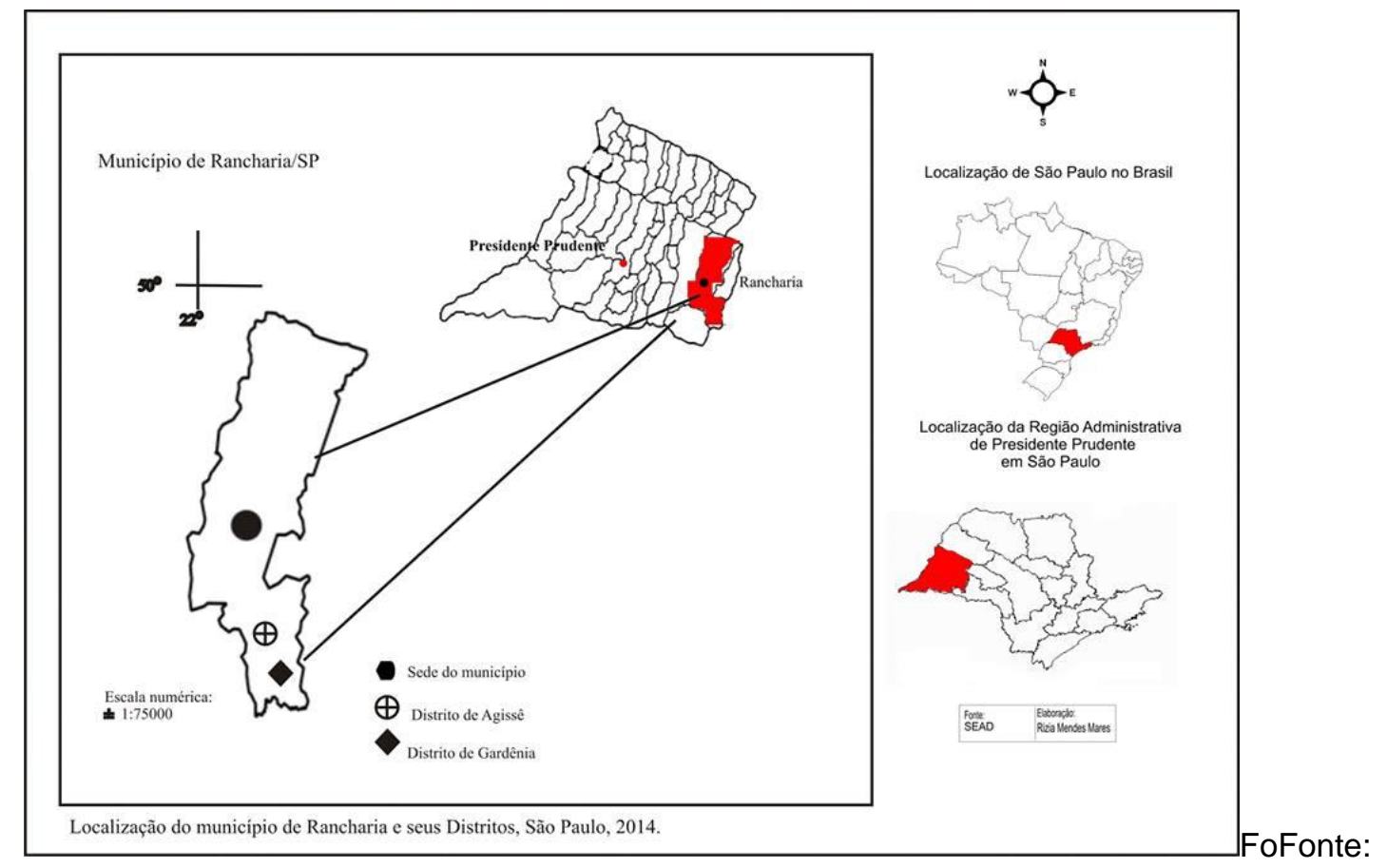

SEADE, 2014. Org. de SOUZA, 2014.

\footnotetext{
${ }^{4}$ De acordo com Souza (2010 apud SOUZA, 2012) o conceito socioespacial foi adotado por reconhecer que as mudanças que ocorrem no espaço interferem simultaneamente nas relações sociais em num contexto de mudanças na apropriação e uso por atividades distintas da precedente.
} 
Destarte, esse estudo tem o objetivo de apresentar a relevância de se traçar um diálogo entre a geografia e o turismo no âmbito escolar, em um contexto de mudanças no uso e a apropriação do espaço por essa atividade. Busca-se através do dos conceitos de reestruturação produtiva e, abordagem geográfica do turismo, discutir a necessidade do envolvimento direto dos sujeitos (alunos e professores do segundo ciclo do $9^{\circ}$ ano do ensino fundamental de uma escola municipal) com o meio, para que apreendam as dinâmicas que ocorrem em seu próprio lugar. As questões que se investigam são: Como os professores de uma escola municipal (Escola Municipal de Ensino Fundamental e Educação Infantil - EMEFEl "Carlos Bueno de Toledo") trabalham a questão das dinâmicas que ocorrem no meio em que o aluno está inserido? A inserção dos sujeitos (alunos/professores) como colaboradores em uma pesquisa em desenvolvimento contribuem para a conscientização da relevância de se adotar práticas significativas, voltadas para o cotidiano do aluno? O que os sujeitos perceberam?

Desse modo, esse estudo tem um caráter exploratório descritivo, com procedimentos metodológicos baseados em revisão bibliográficas, documentais e pesquisa empírica. Para tanto, além dessa introdução, esse estudo está estruturado em três partes, a primeira busca apresentar um breve contexto do Distrito de gardênia, a segunda apresenta as contribuições da abordagem geográfica do turismo, o terceiro os resultados obtidos com as pesquisas empíricas e por fim as considerações finais.

\section{O DISTRITO DE GARDÊNIA NO CONTEXTO DE MUDANÇAS NO USO E A APROPRIAÇÃO DO ESPAÇO}

Conforme exposto por Souza (2012) a política governamental de modernização da agricultura iniciada na década de 1950, alterou a dinâmica do Distrito de Gardênia, que se comparado a outros períodos históricos (ciclo do algodão, por exemplo) deixou de atrair mão de obra braçal para a agricultura. Esse fenômeno de acordo com Carlos (2008 apud SOUZA, 2012) é próprio do caráter 


\title{
Periódica Eletronica ISSN 1980-0827

fugaz das relações produtivas que, a cada momento o espaço passa a ser produzido de acordo com as necessidades da época.

Desse modo, Souza (2012) expõe que a contínua perda populacional (Tabela 1) em virtude da mecanização da agricultura, a mudança na base técnica produtiva que, veio substituir o sistema rudimentar de exploração da terra, a introdução da monocultura da cana-de-açúcar, notadamente, ocupando 47, 4\% da área total do Distrito trouxe implicações socioespaciais ${ }^{5}$, fazendo com que o Distrito perdesse seu dinamismo populacional conquistado até a década de 1960 com a cultura algodão (Figura 2).

Tabela 1: População rural e urbana \% Rancharia/SP e seus Distritos.

\begin{tabular}{c|c|c|c|c|c|c|c|c|c|c}
\hline & \multicolumn{2}{|c|}{1970} & \multicolumn{2}{c|}{1980} & \multicolumn{2}{c|}{1991} & \multicolumn{2}{c|}{$\mathbf{2 0 0 0}$} & \multicolumn{2}{c}{$\mathbf{2 0 1 0}$} \\
\hline & Urbana & Rural & Urbana & Rural & Urbana & Rural & Urbana & Rural & Urbana & Rural \\
\hline Rancharia & $79,4 \%$ & $20,6 \%$ & $83,2 \%$ & $16,8 \%$ & $89,5 \%$ & $10,5 \%$ & $86,8 \%$ & $13,2 \%$ & $89,7 \%$ & $10,3 \%$ \\
Agissê & $13,7 \%$ & $86,3 \%$ & $17,5 \%$ & $82,5 \%$ & $26,5 \%$ & $73,5 \%$ & $41,5 \%$ & $58,5 \%$ & $37,6 \%$ & $62,4 \%$ \\
Gardênia & $16,7 \%$ & $83,3 \%$ & $40,6 \%$ & $59,4 \%$ & $53,1 \%$ & $46,9 \%$ & $67,1 \%$ & $32,9 \%$ & $72,4 \%$ & $27,6 \%$ \\
\hline
\end{tabular}
Fonte: IBGE, Censos Demográficos. Org. SOUZA, 2012.

Consequentemente, expõe Souza (2012), que na tentativa de amenizar o quadro de fragilidade socioeconômica e o decréscimo populacional no Distrito, e, por possuir um conjunto paisagístico em potencial foram previstas na Lei Municipal $\mathrm{n}^{\circ}$ 818/96 em seu artigo $6^{\circ}$, no que dispõe sobre as Diretrizes Orçamentárias para 0 exercício de 1997:

\begin{abstract}
Ações que consistiam em formular um projeto de aproveitamento de potencialidades turísticas, dando ênfase ao Balneário Municipal e ao lago da Represa Capivara no Distrito de Gardênia, com vista à atração de investimentos e a geração de empregos. (PREFEITURA MUNICIPAL DE RANCHARIA, SECRETARIA DO PLANEJAMENTO, 2012 apud SOUZA, 2012, p. $53-54)$.
\end{abstract}

Desta forma, de acordo com Braun (2011), com o Programa de Municipalização do Turismo (PMT) na década de 1994 instituído pela Organização Mundial do Turismo (OMT), possibilitou que a Prefeitura Municipal de Rancharia estabelecesse parcerias com o Serviço Brasileiro de Apoio às Micro e Pequenas

\footnotetext{
${ }^{5}$ Tomando por base Souza (2010), o conceito de socioespacial compreende o conjunto articulado de mudanças que alteram e influenciam simultaneamente, as relações sociais e espaciais.
} 


\section{- Periádica Eletrânico

Empresas (SEBRAE) e alguns setores privados. Nesse sentido, foram ministradas oficinas, e realizados levantamentos sobre as potencialidades paisagísticas, culturais e gastronômicas no Distrito, culminando num evento demonstrativo (SOUZA, 2012).

Entretanto, essa proposta inicial não se efetivou como tensionado, pois mesmo com os consequentes aprimoramentos dos programas, como a inserção do Município de Rancharia no Circuito Turístico Oeste $\operatorname{Rios}^{6}$ em 2010, a criação de uma Secretaria do Turismo em 2005 (SECTEL), não garantiu que o turismo no Distrito prosperasse e alavancasse a economia local. Portanto, foi observado que os empreendimentos turísticos (pesqueiros, ranchos e condomínios de segundas residências) se encontram atualmente isolados, sem o envolvimento da população local, e com uma série de adversidades, como apropriação de áreas de preservação, degradação ambiental e, sobretudo, sem o planejamento, e gerenciamento que a atividade exige (SOUZA, 2012).

Sabe-se que dentre os requisitos para um desenvolvimento turístico com qualidade e com menos impacto possível, é imprescindível o envolvimento da comunidade local nos projetos que se pretende implementar, e para tanto, consideramos fundamental o papel da educação na formação do saber pensar sobre seu próprio meio. Por conseguinte, considerando que no $9^{\circ}$ ano, em especial, se defende uma nova concepção de ensino de geografia, em que se priorize debater as mudanças impostas pelo meio técnico - cientifico - informacional, contextualizado em sala de aula e fora dela que influenciam todas as escalas espaciais. (SÃO PAULO, 2011).

\section{A RELEVÂNCIA DA ABORDAGEM GEOGRÁFICA DO TURISMO NO ENSINO DE GEOGRAFIA}

O ensino de geografia se fundamenta em estudar, apreender o espaço geográfico de forma contextualizada com a realidade em que os alunos estão inseridos. Os conteúdos no quadro de conteúdos e habilidades a serem

\footnotetext{
${ }^{6}$ O Circuito Turístico Oeste Rios compreende um projeto com foco no turismo, cultura e artesanato, e agrupa dois territórios cercados pelo Rio Paraná e o Rio Paranapanema. Tem como objetivo "desenvolver e fortalecer a região através do setor do turismo de forma sustentável, buscando o desenvolvimento regional, aumentando a competitividade do setor em nível nacional, transformando e consolidando a região como polo turístico". (SEBRAE, 2010).
} 


\section{Periódica Eletrânico

desenvolvidas, retratam a questão do turismo e o consumo do lugar, e esse fato nos instiga de empreendermos esse estudo com a perspectiva da abordagem geográfica do turismo envolvendo os alunos do 9 ํ ano de uma escola municipal no Distrito.

Para Vesentini (1999), o papel do ensino da geografia no entendimento do mundo moderno deve dar ferramentas ao aluno, e a partir dela colaborar para a compreensão dos fenômenos que ocorrem além do local em que vivem. Portanto em consonância com o autor (1999), partimos da ideia de que se faz necessário um estudo no Distrito que possa através da abordagem geográfica, mas não de maneira isolada de outras disciplinas, levar os sujeitos (alunos e professores) a perceberem a relevância de apreender as mudanças que vem ocorrendo em seu cotidiano.

Esse fato se tornou mais evidente quando constatamos que nos planos de geografia do segundo ciclo $\left(1^{\circ}\right.$ ao $4^{\circ}$ bimestre de 2014) em especial, há o predomínio de conteúdos que focam em fenômenos que ocorrem em outras escalas espaciais, em detrimento do que ocorre na realidade dos alunos. Desse modo, inferimos que de modo geral, a carência da sensibilização de toda comunidade escolar (gestores, professores e alunos) perante a necessidade de práticas e conteúdos condizentes com a realidade local, a burocratização do sistema escolar, entre outros fatores que consequentemente serão desvelados, são alguns indícios desse contexto educativo.

Peretti (2002) ressalta que:

Diante da grande expressividade do turismo, a geografia não poderia furtar-se de realizar a análise e interpretação das mudanças espaciais causadas pela atividade turística, buscando a compreensão da estrutura e dos processos que deram causas a essas transformações (PERETTI, 2002, p. 6).

A autora citada anteriormente acrescenta que compreender o turismo por meio do enfoque geográfico é muito relevante, pois a geografia em si lida com as relações sociedade/natureza. Nesse âmbito Silva (2012), afirma que a geografia no contexto atual de transformações incitadas pela globalização, tem se apresentado como uma ciência que mais tem contribuído no entendimento de temas emergentes como o turismo.

À vista disso, ratificamos a relevância de desenvolver esse trabalho com os alunos do $9^{\circ}$ da Escola Municipal "Carlos Bueno de Toledo" no Distrito, pois, por meio da abordagem geográfica do turismo possibilitaremos aos sujeitos (alunos, 
professores, gestores) reconhecer a necessidade de perceberem que as dinâmicas que ocorrem em seu cotidiano ocorrem simultaneamente em outras escalas.

Reiteramos que a perspectiva de se trabalhar o enfoque geográfico do turismo no contexto local partiu da necessidade de levar a conscientização dos sujeitos em questão de novas práticas, de se desprender do currículo imposto, de transpor os limites da sala de aula, enfim, de terem embasamentos para repensarem um novo plano de aula (Figura 2), um novo Projeto Político Pedagógico condizente com as dinâmicas socioespaciais locais.

Figura 2: Distrito de Gardênia, apresentação de pesquisa na escola.

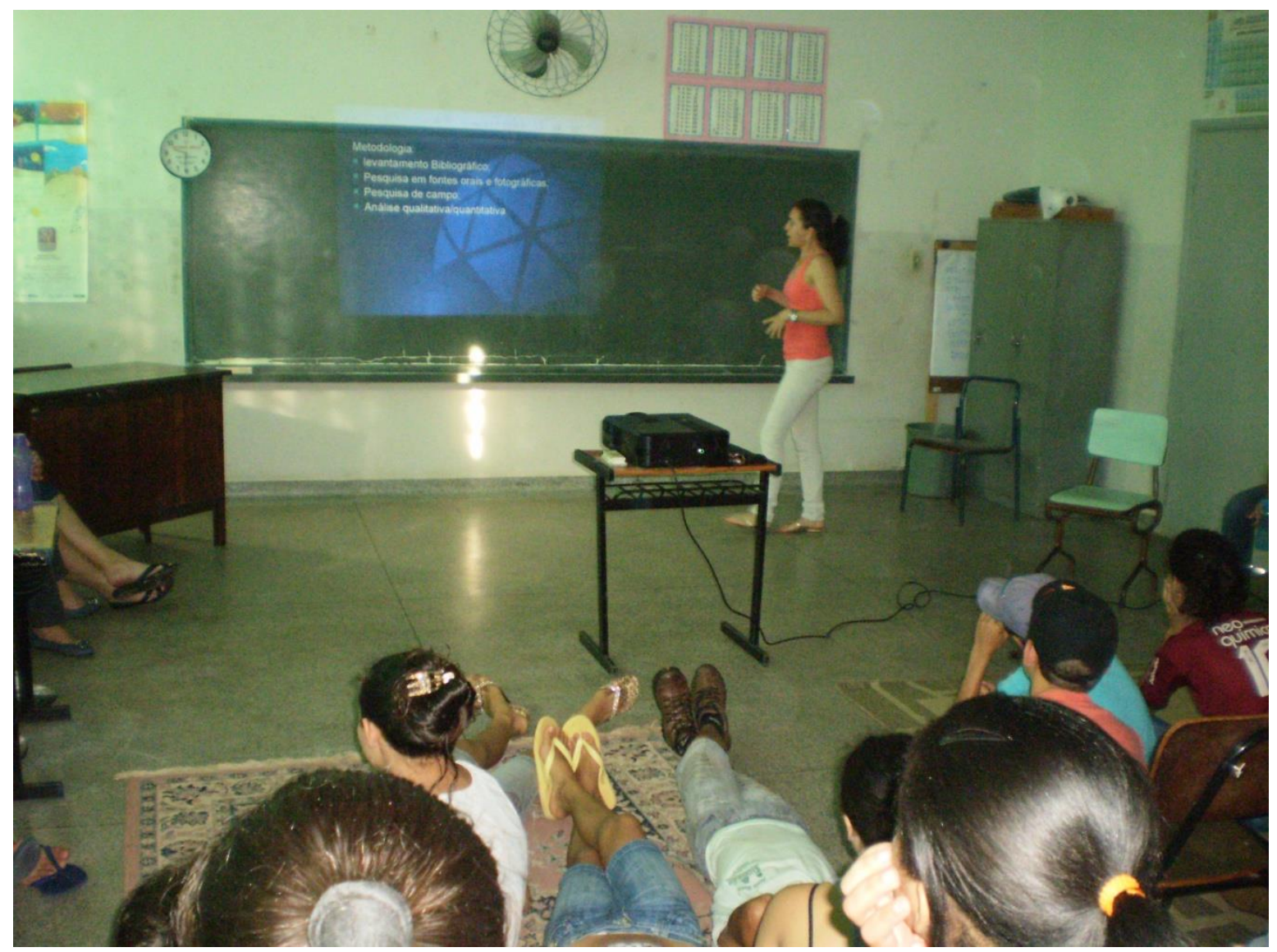

Fonte: Souza, 2014.

Observamos que essa perspectiva (turismo/educação) é muito relevante a ser discutida, pois não houve ainda um trabalho aprofundado sobre os novos usos e apropriação do espaço no Distrito, como suas implicações nas práticas espaciais locais. Por conseguinte, consideramos que desprender de conteúdos que abarcam outras escalas apenas não é suficiente para uma formação exigida no enfrentamento 
dos desafios cotidianos; que os alunos se interessaram, e se preocuparam com os rebatimentos dessas novas dinâmicas (turismo de pesca, monocultura da cana - de açúcar etc.) sim, notadamente, assim como quais os rebatimentos dessas dinâmicas em voga para um futuro próximo. Demonstraram ainda, preocupação no tocante ao decréscimo populacional, ao desemprego, ao envelhecimento da população local etc; os professores, apesar da postura arredia inicial, e as justificativas da grande quantidade de tarefas a serem cumpridas "não deixar brechas para se trabalhar essas questões", também se envolveram em debater com os alunos e pesquisadores sobre a realidade local. Em contrapartida, mesmo participando e vivenciando uma situação prática de pesquisa (aplicação de questionários) (Figura 3), os alunos demonstraram na devolutiva, pouco interesse em relação aos resultados sobre uma pesquisa de demanda em uma manifestação cultural (Festa de São Sebastião).

Figura 3: Distrito de Gardênia, Festa de São Sebastião, professores e alunos aplicando entrevistas.

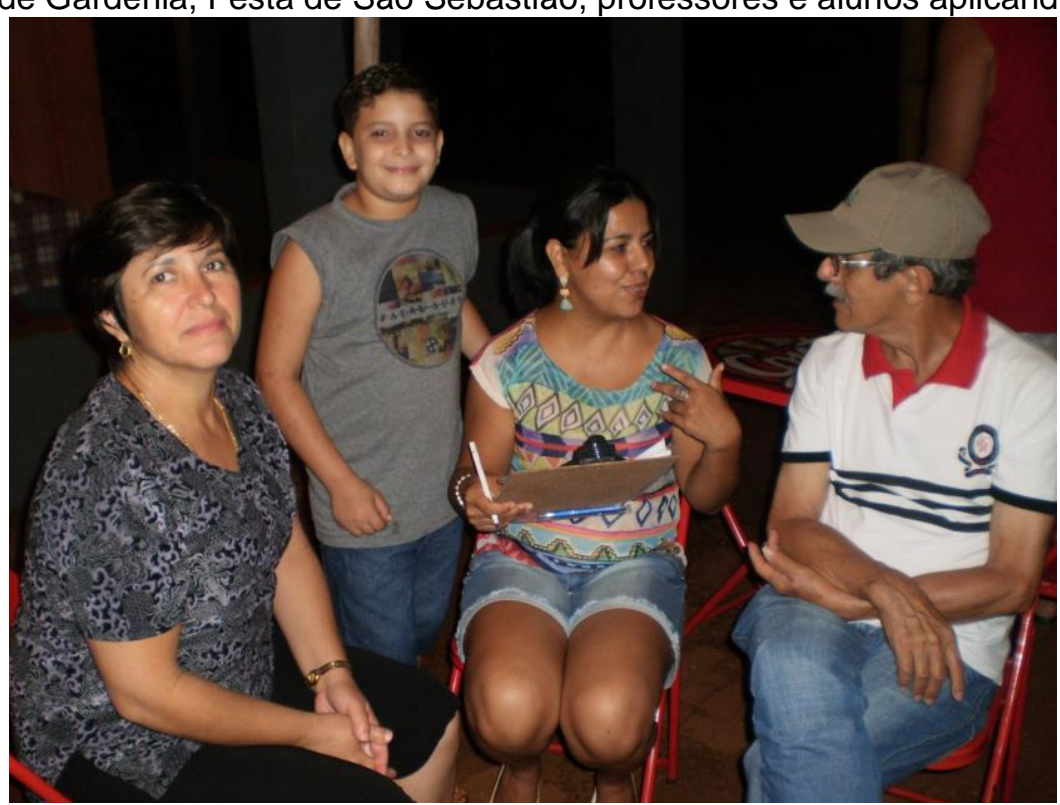

Fonte: pesquisa de campo, 2014.

Assim, vem indicar a importância de um trabalho mais aprofundado por parte da comunidade escolar visando a preservação da cultura popular local, que conforme observado em pesquisa atrai um considerável público para sua apreciação, a população local participante procura zelar pela sua perpetuação e a veem como um atrativo turístico em potencial.

\section{CONCLUSÕES}


Os resultados obtidos em pesquisas no tocante ao uso e apropriação do turismo de pesca no Distrito, bem como suas implicações nas práticas espaciais da população local, a iniciativa precursora da pesquisa colaborativa, em que professores, alunos e pesquisadores são sujeitos ativos no desvelar de opiniões e tramas travadas em uma manifestação cultural local, são muito relevantes para a percepção das dinâmicas que ocorrem em seu cotidiano. Desse modo, possibilita conhecer as principais deficiências na percepção do objeto em questão e assim, trabalhar conjuntamente para que todos os sujeitos envolvidos reconheçam, apreendam e atuem frente aos fenômenos que ocorrem continuamente em seu lugar e no mundo.

\section{REFERÊNCIAS}

HESPANHOL, Antonio Nivaldo; HESPANHOL, Rosangela Aparecida Medeiros. Dinâmica do Espaço Rural e Novas Perspectivas de Análise das Relações Campo-Cidade no Brasil. Terra Livre, v. 2, p. 133-148, 2006.

PERETTI, Glaúcia Aparecida Rosa Cintra. Proposta de conscientização turística na EE 18 de junho de Presidente Epitácio-SP: uma experiência de como trabalhar o tema turismo nas escolas de ensino fundamental. 2002.121p. Dissertação (mestrado em geografia)-FCT/UNESP, Presidente Prudente/SP.

SEBRAE. Serviço Brasileiro de Apoio a Micro e Pequenas Empresas. Circuito Turístico Oeste Rios. 2010.

SILVA, Carlos Henrique Costa. O turismo e a produção do espaço: perfil geográfico de uma prática socioespacial. Geografia Ensino \& Pesquisa, v. 16, n.2. p. 47-63, maio/ago, 2012.

SÃO PAULO (Estado) Secretaria da Educação. Currículo do Estado de São Paulo: Ciências Humanas e Suas Tecnologias/ Secretaria da Educação; Coordenação geral, Maria Inês Fini; Coordenação de área, Paulo Miceli. - 1. ed. atual. - São Paulo: SE, 2011. 152 p.

SOUZA, Marcelo Lopes de. Como o Estado, apesar do Estado, contra o Estado: os movimentos urbanos e suas práticas espaciais, entre a luta institucional e a ação direta. Cidades, v. 7. n. 11, 2010.

SOUZA, Sueli Aparecida de. Transformações Socioespaciais no Distrito de Gardênia, Município de Rancharia - SP. 2012. 116 f. Trabalho de conclusão de curso (Bacharelado em geografia) - UNESP/ Presidente Prudente, 2012.

VECENTINI, José Willian. Educação e ensino da geografia: instrumentos de dominação e/ou libertação. In: CARLOS, Ana Fana Alessandri. Geografia em sala de aula. São Paulo: contexto, 1999. 